\title{
Respiratory symptoms in children of low birth weight
}

\author{
K N CHAN, A ELLIMAN, E BRYAN, AND M SILVERMAN
}

Department of Paediatrics and Neonatal Medicine, Royal Postgraduate Medical School, Hammersmith Hospital, and Queen Charlotte's Maternity Hospital, London

SUMMARY We recorded the respiratory history by questionnaire in a 7 year old cohort of children whose birth weight was under $2000 \mathrm{~g}$ and an unselected reference group of local schoolchildren of the same age. Complete data were obtained in 121 low birthweight children ( $90 \%$ of those studied): 62 who had no neonatal respiratory illness, 25 who had oxygen treatment only, and 34 who received mechanical ventilation (of whom 10 had bronchopulmonary dysplasia). The low birthweight children were no more likely to wheeze than the reference group, but frequent and troublesome cough was significantly more common, especially among children of very low birth weight (under $1500 \mathrm{~g}$ ) who had received neonatal respiratory treatment. Neonatal mechanical ventilation was not associated with increased symptoms when compared with neonatal oxygen treatment alone. The prevalence of cough at the age of 7 was independently associated with the level of neonatal intensive care as defined by oxygen score. Although there was no excess of wheeze in the cohort compared with the reference group, there was a weak correlation between wheeze and the neonatal oxygen score as well as with maternal smoking. Loss of schooling due to respiratory symptoms in the nine months before this study was no greater in children of low birth weight than in the reference group.

The literature contains a remarkable lack of information on the long term respiratory symptoms that are experienced by children of low birth weight. Our knowledge is based on a number of retrospective studies designed primarily to evaluate lung function. These studies concern small, heterogeneous groups of survivors selected on the basis of a number of different criteria. It is nevertheless fairly well established that respiratory illness and chest symptoms are common in the first year of life in those who survive neonatal respiratory distress syndrome. ${ }^{1-7}$ The severity of these early symptoms appears to be related to the intensity of respiratory treatment in the neonatal period. ${ }^{78}$ During the first year most of the survivors improve rapidly in respect of both clinical features and lung function, ${ }^{79}$ so that by school age, children are generally symptom free and are presumed to have recovered completely. ${ }^{10-12}$ These conclusions are based for the most part on studies that were carried out at a time when there were relatively few long term very low birthweight survivors. Recently, with increased survival of very small infants, a number of studies have shown abnormal airway function at school age. ${ }^{13-15}$

Little is known, however, of the clinical importance of these physiological findings as very few authors have attempted to relate their measurements to symptoms. Those who have done so have been concerned only with whether or not the subjects were 'symptomatic' in comparison with either 'normal' or 'historical' controls rather than with a truly representative random sample of children from the general population who were born at the same time. In addition, most studies have dealt with the outcome in highly selected groups of subjects with, for instance, respiratory distress syndrome or bronchopulmonary dysplasia. There is no published study that has systematically examined the long term respiratory morbidity of prematurely born children with and without neonatal respiratory illness.

The present study had two specific objectives. Firstly, we aimed to examine the long term respiratory morbidity in a cohort of age specific and birthweight specific low birthweight children (less than $2000 \mathrm{~g}$ ) at the age of 7 years and to compare them with an unselected reference population of local schoolchildren of the same age. Secondly, we wished to test the hypothesis that respiratory symptoms in the low birthweight children, if present, were a consequence of neonatal respiratory illness and its treatment. 


\section{Subjects and methods}

\section{SUBJECTS}

Details of the low birthweight cohort and the reference group of children have already been described.$^{16}$ Briefly, of the 292 infants of under $2000 \mathrm{~g}$ birth weight who were admitted to the neonatal units of Hammersmith and Queen Charlotte's Maternity Hospitals in the 12 month period (June 1979-May 1980), 216 were alive at 7 years. Of these, 134 were seen and examined, although not all were capable of completing the lung function tests. A group of 123 unselected local schoolchildren born in the same period was examined concurrently with the low birthweight cohort and formed the reference group. Children were selected from the register of three local schools on the basis of their date of birth, irrespective of their social and family background. No subject was excluded on the basis of current symptoms, or of a personal or family history of respiratory illness.

Perinatal data on the low birthweight children had been recorded at the time of discharge from the neonatal units. From this file, we extracted information on a whole range of features that might have value as predictors of respiratory symptoms later in childhood. Among many factors, these included birth weight, gestational age, presence of neonatal respiratory illness and its complications, duration of oxygen and mechanical ventilation treatment, peak inspiratory ventilator pressure used, and maternal cigarette consumption during pregnancy.

The studies were approved by local ethics committees and the education authority. Informed consent was obtained from parents of both the low birthweight cohort and the local schoolchildren.

\section{PROTOCOL}

Identical questionnaires were used to record clinical, social, and family history for the low birthweight cohort and the reference population. (A copy of the questionnaire can be obtained from the corresponding author.) The low birthweight children were seen in hospital lung function clinics together with their parents. We were unable to obtain their clinical history by direct interview. On the other hand, the reference children were seen at school without their parents, who were therefore asked to complete both a consent form and a questionnaire at home and to return them to the school. In the questionnaire we asked if the child had symptoms of cough and wheeze, if the symptoms occurred occasionally or frequently, if the child had previously had treatment or had been in hospital for chest illness and if any members of the close family (natural parents and siblings) had asthma, hay fever, or eczema. We asked about the occupation and the average number of cigarettes currently consumed per day by each parent. Information on home condition, such as the type of fuel used for cooking and heating, if the home was cold or damp, and if any pets were kept, was also sought. We recorded whether the child had had a cold within the previous four weeks.

Even though the same questions were asked, we could not be certain about the comparability of the questionnaire responses in the two populations of children, as the methods used, interview or self administration, were different. For this reason, at the end of our study parents of all the children in the study were asked to complete a second self administered questionnaire, which was again identical for both groups of children. Those for the low birthweight cohort were sent by mail, whereas those of the reference group were delivered by their class teachers. This questionnaire allowed us to determine repeatability and to ask a few additional questions.

In order to improve its return rate, questions concerning parental social class and home conditions were omitted from the second questionnaire. Instead, further details of current symptoms were sought and questions concerning previous chest infections, admissions to hospital, atopic diathesis (asthma, hay fever, and eczema) in the family, and parental cigarette consumption were repeated. We also asked if smoking habits had changed in the previous few months. The second questionnaire was administered at the same time for both groups of children. In order to ensure that the questionnaire was completely filled, the parents were asked to indicate those questions that they did not understand or could not answer. The mean time interval between the two questionnaires for the low birthweight children was about five months whereas for the reference group it was three months. A final total of $95 \%$ and $89 \%$ of the questionnaires were returned by the parents of the low birthweight and reference groups respectively. To ensure comparability between low birthweight cohort and the reference population, the second questionnaire formed most of the data base for this analysis. Only the parents' occupation and home conditions were based on the first questionnaire.

Lung function and bronchial responsiveness to histamine were measured on all children who did not have a recent respiratory infection. Details are described elsewhere. ${ }^{16}$ Skin prick tests against common allergens, namely house dust mite, group B pollens, and cat fur together with a control solution (Bencard) were carried out on the low birthweight children only. Subjects were considered atopic when a weal of at least $2 \mathrm{~mm}$ in diameter was present in 
response to any one of the three allergens in the absence of a similar response to the control solution.

\section{DEFINITIONS OF RESPIRATORY SYMPTOMS}

AND ILLNESSES

Wheeze and cough, whether they occurred unprovoked or in association with common colds or with exercise were ascertained separately. 'Wheeze with colds' was defined as a positive response obtained to both the questions 'Has your child ever had wheezy chest (whistling noise) with common colds?' and 'If yes, does it happen frequently?' Wheeze with exercise was defined as an affirmative response to the question 'Does exercise make his/her chest wheezy?' Those children in whom a positive response was obtained for both of the questions 'Has he/she ever had troublesome cough following common colds' and 'If yes, does it happen frequently?' were referred to as having 'troublesome cough with colds'. Those in whom a positive response was obtained to the question 'Does exercise make him/her cough?' were considered to have 'cough with exercise'. Children whose parents answered 'Yes' to both of the questions 'Does he/she cough at night not due to colds?' and 'If yes, does it happen frequently?' were considered to have 'frequent nocturnal cough'. Wheeze and daytime and nocturnal cough were considered separately.

Previous respiratory illnesses were defined as an affirmative response to a series of questions of the form 'Has he/she ever had (i) asthma (ii) whooping cough (iii) croup (stridor) (iv) chest infection (v) an admission to hospital because of chest trouble?' The age at which each of these first occurred and the number of episodes of each were also asked. A family history of eczema, hay fever, and asthma was sought among first degree relatives (natural parents and siblings). Parents who were current smokers and lived in the same household as the subjects were defined as current smokers.

\section{STATISTICAL ANALYSIS}

The extent of agreement between the responses to identical questions in the two questionnaires was determined by the index of repeatability, known as the Cohen's kappa $(x) .{ }^{17}$ This index takes into account the chance agreement that could have occurred in certain questions to which a positive response is low.

Respiratory outcome at 7 years was examined by dividing the low birthweight cohort into subgroups according to birth weight (above or below $1500 \mathrm{~g}$ ) and the presence or absence of respiratory illness in the neonatal period. 'No neonatal respiratory illness' was defined as the absence of respiratory signs or as the need for oxygen treatment at a concentration of no more than $40 \%$ for no more than six hours. 'Oxygen only' was defined as neonatal respiratory illness needing oxygen treatment of over $40 \%$ or for over six hours but mechanical ventilation, if any, for less than three hours. 'Mechanical ventilation' was defined by the need for over three hours' mechanical ventilation. An oxygen dependent group of 10 children with bronchopulmonary dysplasia was defined by their oxygen dependency at 30 days of postnatal age. All 10 weighed under $1500 \mathrm{~g}$ at birth and had required mechanical ventilation (mean duration of 311 hours, range 18 to 916 ).

In order to examine the association between long term symptomatology and the level of neonatal intensive treatment, an oxygen score that reflected both the duration and intensity of treatment in the neonatal period was computed. This was derived by allocating one point for each hour of oxygen treatment with an inspired oxygen concentration between $22 \%$ and $40 \%$, two points for each hour between 41 and $60 \%$, three points for each hour between 61 and $80 \%$, and four points for each hour between 81 and $100 \%$.

Crude examination of the association between perinatal and other risk factors and long term symptomatology was initially analysed using $\chi^{2}$ tests. For convenience the symptoms were considered present if they were reported to be still frequent, irrespective of whether they occurred unprovoked or after colds. Wheeze and cough were considered separately. As no allowance had been made for multiple tests performed, it was therefore prudent to accept a p value of $<0 \cdot 01$ as indicative of statistical differences between groups.

Multiple logistic regression analysis was used to test the hypothetical association between symptoms and perinatal factors allowing for other factors that might also influence the occurrence of symptoms. Generalised linear interactive modelling was adapted for such analysis. ${ }^{18}$

\section{Results}

REPEATABILITY OF QUESTIONNAIRES

Some of the questionnaires were not completely filled. Consequently complete data were available in $121(90 \%)$ and $100(81 \%)$ of the children in the low birthweight and reference groups who attended. Only those subjects with complete information have been included in the following analysis. The overall agreement between the first and second questionnaire within the low birthweight and the reference groups was no different but the $x$ values were generally higher for the low birthweight cohort (table 1). Questions about asthma were significantly 
Table 1 Repeatability of responses to comparable questions in the two questionnaires administered to the parents of 121 low birthweight and 100 reference children

\begin{tabular}{|c|c|c|c|c|}
\hline & \multicolumn{2}{|c|}{ Proportion in agreement } & \multicolumn{2}{|c|}{ Index of repeatability $(x)^{*}$} \\
\hline & $\begin{array}{l}\text { Low } \\
\text { birthweight }\end{array}$ & Reference & $\begin{array}{l}\text { Low } \\
\text { birthweight }\end{array}$ & Reference \\
\hline Previous hospitalisation & 0.96 & 0.97 & $0 \cdot 86$ & 0.75 \\
\hline Cigarette consumption by father $\dagger$ & 0.92 & 0.84 & 0.77 & 0.65 \\
\hline Cigarette consumption by mothert & 0.94 & 0.96 & $0 \cdot 85$ & 0.90 \\
\hline Asthma in subjects & 0.98 & 0.94 & $0.91 \S$ & 0.72 \\
\hline \multicolumn{5}{|l|}{ Family history: $\ddagger$} \\
\hline Asthma & 0.99 & 0.96 & $0.88 \S$ & 0.71 \\
\hline Eczema & 0.94 & 0.96 & 0.53 & 0.65 \\
\hline Hay fever & 0.95 & 0.94 & 0.75 & 0.65 \\
\hline
\end{tabular}

${ }^{*}$ Cohen's kappa $(x)$ is defined as the observed agreement in excess of that expected as a proportion of the total excess agreement that is possible.

†Agreement defined as within $20 \%$ of daily mean.

¥Natural parents and siblings.

§Significance of difference between groups by $z$ test: $p<0 \cdot 01$.

more consistently answered by parents of the low birthweight cohort.

FAMILY, HOME, AND ENVIRONMENTAL

BACKGROUND

There was no difference in the atopic background between the low birthweight and the reference group, as evidenced by the similarity in the prevalence of familial asthma and hay fever (table 2).

More mothers than fathers were current smokers in both groups. This was in part due to the fact that mothers only were present in the many single parent households, although the prevalence of maternal smoking remained higher than that of paternal

Table 2 Family, environmental, and social background in the low birthweight and the reference group at 7 years. Results are No (\%)

\begin{tabular}{lll}
\hline & $\begin{array}{l}\text { Low } \\
\text { birthweight } \\
(n=121)\end{array}$ & $\begin{array}{l}\text { Reference } \\
(n=100)\end{array}$ \\
\hline Asthma in either parent & $13(11)$ & $13(13)$ \\
Asthma in close family* & $20(17)$ & $18(18)$ \\
Hay fever in either parent & $34(28)$ & $30(30)$ \\
Hay fever in close family* & $38(31)$ & $35(35)$ \\
Father a current smoker & $27(22)^{* *}$ & $36(36)$ \\
Mother a current smoker & $39(32)$ & $43(43)$ \\
Home cooking with gas stove & $80(66)$ & $69(69)$ \\
Home cold or damp & $18(15)$ & $21(21)$ \\
Low socioeconomic status $\dagger$ & $23(19)^{* * *}$ & $42(42)$ \\
Single parent family & $14(12)$ & $18(18)$ \\
\hline
\end{tabular}

*Included natural parents and siblings.

†Parents who were either unskilled or unemployed.

Significance of difference between groups by $\chi^{2}$ test: ${ }^{* *} p<0.01$; ${ }^{* * *} \mathrm{p}<0.001$. smoking even when making allowance for this factor. There was, however, no difference in the prevalence of current maternal smoking between the two groups. The parents of the reference group were of lower socioeconomic status (defined as unskilled or unemployed). The fact that there were more single mothers in the reference group who were not in any form of employment contributed to much of the difference. A greater proportion of fathers of reference children were smokers. There was, however, no significant difference in adverse environmental factors, such as reported poor housing and use of gas cooking at home.

HISTORY

A history of asthma was similar in the two groups of children (table 3 ). This is consistent with the fact that a family history of asthma was no more common in the low birthweight cohort than in the reference group (table 2).

A history of whooping cough, previous chest infection, and a previous admission to hospital for

Table 3 Respiratory history obtained at 7 years in the low birthweight and the reference group. Results are No (\%)

\begin{tabular}{|c|c|c|}
\hline & $\begin{array}{l}\text { Low } \\
\text { birthweight } \\
(n=121)\end{array}$ & $\begin{array}{l}\text { Reference } \\
(n=100)\end{array}$ \\
\hline Asthma & $13(11)$ & $13(13)$ \\
\hline Whooping cough & $29(24)^{*}$ & $11(11)$ \\
\hline Croup (stridor) & $13(11)$ & $4(4)$ \\
\hline Previous chest infections & $19(16)^{*}$ & 7 (7) \\
\hline $\begin{array}{l}\text { Previous hospitalisation for } \\
\text { chest illness }\end{array}$ & $24(20)^{*}$ & 8 (8) \\
\hline
\end{tabular}

Significance of difference between groups by $\chi^{2}$ test: ${ }^{*} p<0.05$. 
chest illness was twice as common in the low birthweight cohort as in the reference group $(p<0 \cdot 05)$. Because the low birthweight children had been seen at special follow up clinics since birth, we were able to establish that $74 \%$ and $75 \%$ of the reported chest illnesses and admissions to hospital respectively had been documented in the first 2 years of life. The prevalence of chest infection recorded during the first 2 years was $2 \%, 20 \%$, $18 \%$, and $30 \%$ for children who had no neonatal respiratory illness, oxygen treatment only, mechanical ventilation, and bronchopulmonary dysplasia, respectively. For admission to hospital for respiratory illness, the figures were $6 \%, 12 \%, 18 \%$, and $40 \%$, respectively. In the nine months before the study there was no significant difference in the loss of schooling due to respiratory illness between the low birthweight and the reference group (mean loss of schooling: low birth weight 4.7 days, reference 3.8 days).

Table 4 Respiratory symptoms in the low birthweight cohort and the reference group at 7 years. Results are No $(\%)$

\begin{tabular}{llc}
\hline & $\begin{array}{l}\text { Low } \\
\text { birthweight } \\
(n=121)\end{array}$ & $\begin{array}{l}\text { Reference } \\
(n=100)\end{array}$ \\
\hline $\begin{array}{l}\text { Wheeze with exercise unrelated } \\
\text { to colds }\end{array}$ & $13(11)$ & $9(9)$ \\
$\begin{array}{l}\text { Wheeze with or without colds } \\
\text { Cough with exercise unrelated } \\
\text { to colds }\end{array}$ & $19(16)$ & $16(16)$ \\
$\begin{array}{l}\text { Cough with or without colds } \\
\text { Frequent nocturnal cough } \\
\text { unrelated to colds }\end{array}$ & $26(22)^{*}$ & $10(10)$ \\
\hline $\begin{array}{l}\text { Significance of difference between groups by } \chi^{2} \text { test: }{ }^{*} \mathrm{p}<0.05 ; \\
{ }^{* *} \mathrm{p}<0.01 .\end{array}$ & $11(34)^{* *}$ & $17(17)$ \\
\end{tabular}

\section{CURRENT SYMPTOMS}

The overall prevalence of wheeze, whether or not it occurred in association with common colds or with exercise, was similar in the low birthweight cohort and in the reference group (table 4). The prevalence of daytime cough was twice as common in the low birthweight subjects, though the prevalence of frequent nocturnal cough was almost identical. The overall prevalence of symptoms (all categories combined) in the low birthweight children was only marginally higher than that of the reference group $(p=0.05)$.

In the reference group wheeze, but not cough, was significantly associated with a history of asthma in the family $(\mathrm{p}<0.01)$ (table 5). Daytime cough (but not nocturnal cough) was weakly associated with maternal smoking $(p<0.05)$ but not with smoking by other members in the household. There was, however, no 'dose-effect' association between the number of cigarettes that mothers smoked per day and wheezing. There was no association between symptoms and the sex, or ethnic or socioeconomic background of the children. Gas cooking and poor housing (cold or damp) were not associated with increased symptoms in the children.

In contrast, in the low birthweight cohort, the association between wheeze and a family history of asthma did not reach a level of significance $(p=0.06)$ and there was no association between the symptom? and positive skin prick tests. There was, however, a significant association between maternal smoking and wheeze $(\mathrm{p}<0.01)$. For cough, when considered separately, there was a borderline association with both maternal smoking and low socioeconomic status $(p<0.05)$, but, as will be seen later, these associations were not significant when other factors were taken into account. Smoking by other household members, sex, and ethnic background of the subjects were not associated with symptoms.

Table 5 Prevalence of symptoms in relation to a family history of asthma, maternal smoking, and low socioeconomic status in the low birthweight and the reference group. Results are No (\%)

\begin{tabular}{|c|c|c|c|c|c|c|}
\hline & \multicolumn{2}{|c|}{ Family history of asthma } & \multicolumn{2}{|c|}{ Maternal smoking } & \multicolumn{2}{|c|}{ Low socioeconomic statust } \\
\hline & Yes & No & Yes & No & Yes & No \\
\hline \multicolumn{7}{|l|}{ Wheeze: } \\
\hline Low birth weight & $6 / 20(30)$ & $13 / 101(13)$ & $11 / 39(28)^{* *}$ & $8 / 82(10)$ & $5 / 23(22)$ & $14 / 98(14)$ \\
\hline \multicolumn{2}{|l|}{ Cough: } & & $9 / 43(21)$ & $7 / 57(12)$ & $6 / 42(14)$ & $10 / 58(17)$ \\
\hline Low birth weight & $9 / 20(45)$ & $32 / 101(32)$ & $18 / 39(46)^{*}$ & $23 / 82(28)$ & $12 / 23(52)^{*}$ & $29 / 98$ (29) \\
\hline Reference & $5 / 18(28)$ & $12 / 82 \quad(15)$ & $11 / 43(26)^{*}$ & $6 / 57$ (11) & $9 / 42(21)$ & $8 / 58$ (14) \\
\hline
\end{tabular}

Significance of association by $\chi^{2}$ test: ${ }^{*} \mathrm{p}<0.05 ;{ }^{* *} \mathrm{p}<0.01$.

(As no allowance has been made for multiple comparisons, the level of significance should be taken as $p<0.01$.)

†Parents who were either unskilled or unemployed. 
Table 6 Multiple logistic regression analysis for the association between neonatal oxygen score and respiratory symptoms at 7 years in the low birthweight cohort allowing for four pertinent variables

\begin{tabular}{llll}
\hline Symptom variable & $\begin{array}{l}\text { Odds } \\
\text { ratio }\end{array}$ & $\begin{array}{l}95 \% \text { Confidence } \\
\text { interval for } \\
\text { odds ratio }\end{array}$ & Probability \\
\hline Wheeze: & & & \\
Family history of asthma & 2.05 & 0.58 to 7.18 & 0.27 \\
Atopic skin test & 2.50 & 0.71 to 8.80 & 0.16 \\
Maternal smoking & 3.39 & 1.13 to $10 \cdot 20$ & 0.03 \\
Low socioeconomic status & 1.29 & 0.35 to 4.75 & 0.70 \\
Neonatal oxygen score* & 1.57 & 1.07 to 2.30 & 0.02 \\
Cough: & & & 0.48 \\
Family history of asthma & 1.43 & 0.49 to 4.22 & 0.25 \\
Atopic skin test & 1.85 & 0.64 to 5.30 & 0.12 \\
Maternal smoking & 1.95 & 0.83 to 4.62 & 0.07 \\
Low socioeconomic status & 2.58 & 0.94 to 7.11 & 0.005
\end{tabular}

Definition: family history of asthma (negative $=0$, positive $=1)$; atopic skin test (negative $=0$, positive $=1$ ); maternal smoking $($ no $=0$, yes $=1)$; low socioeconomic status $($ no $=0$, yes $=1)$.

${ }^{*}$ Defined in text: coded into five levels (as $\left.0-4\right)$ for scores of $0,1-60,61-240,241-960,961-3800$.

The magnitude of the estimated odds ratios is dependent on the integral values.

\section{ASSOCIATION BETWEEN PERINATAL FACTORS AND \\ CHILDHOOD SYMPTOMS}

Wheeze was no more prevalent in the low birthweight children than in the reference group. Nevertheless there was a weak association between the prevalence of wheeze and both the neonatal oxygen score and maternal smoking (table 6).

The prevalence of cough in those who had no neonatal respiratory illness was no higher than in the reference group. It was, however, significantly higher in those who received neonatal respiratory treatment. The difference was largely attributable to the increase in the prevalence of cough in very low birthweight children $(<1500 \mathrm{~g})$ who had neonatal respiratory treatment (figure).

For those who required neonatal respiratory treatment, whether of very or moderately low birth weight (1501-2000 g), mechanical ventilation was not associated with an increase in symptoms at 7 years. The 10 children who were oxygen dependent beyond the neonatal period (those with bronchopulmonary dysplasia) had the highest prevalence of symptoms, but compared with other very low birthweight children without bronchopulmonary dysplasia, the difference was not significant.

The prevalence of asthma was extraordinarily low in the low birthweight children who received neonatal mechanical ventilation $(5.9 \%)$, despite the fact that the prevalence of symptoms in those who received mechanical ventilation (wheeze $26.5 \%$, cough $44 \%$ ) was not different from those who received oxygen treatmènt alone (wheeze $24 \%$, cough $40 \%$ ). The prevalence of previous chest

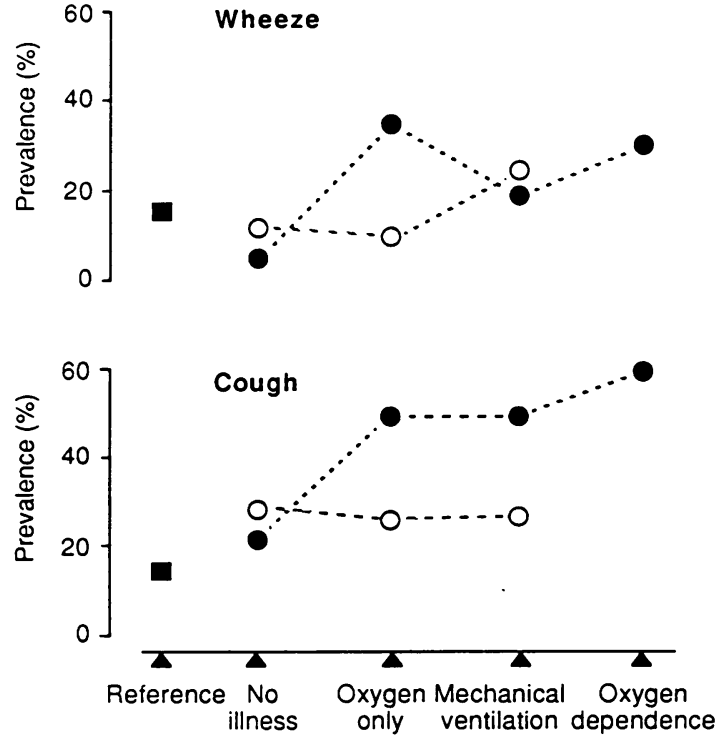

Figure Prevalence of symptoms in the low birthweight and the reference groups in relation to neonatal respiratory treatment and birth weight. Reference group $(n=100)=$ very low birthweight children $(<1500 \mathrm{~g})=0$; and moderately low birthweight children (1501 to $2000 \mathrm{~g})=0$. Of the group of very low birthweight children, 22 had no neonatal respiratory illness, 40 oxygen treatment only, and 14 mechanical ventilation; the numbers for those of moderately low birthweight were 11,16 , and eight, respectively. There were 10 children in the oxygen dependent group, all of whom weighed $<1500 \mathrm{~g}$ at birth. 
infections and admissions to hospital for chest illness in the low birthweight children who had no neonatal respiratory illness was equivalent to that of the reference group, but these features were commoner in those who had neonatal respiratory illness.

Using multiple logistic regression analysis the hypothetical association was confirmed between the level of neonatal intensive care (oxygen score) and symptoms reported at 7 years, allowing for a positive history of asthma in the family, positive skin tests, maternal smoking, and low socioeconomic status (table 6). There was no correlation between oxygen score and other variables considered in the analysis. Addition of variables that reflect the use and extent of neonatal mechanical ventilation, including both its duration and the peak inspiratory pressure required, did not explain any further deviance than oxygen score alone. In addition, the prevalence of wheeze was associated with maternal smoking, but not with any other perinatal factors examined, suggesting that both maternal smoking and oxygen score were independently associated with the symptom. Mothers who smoked were likely to have done so before $(92 \%)$ and during $(79 \%)$ pregnancy, therefore it was not possible to analyse the effect of maternal smoking during pregnancy and during infancy independently.

\section{Discussion}

\section{SUBJECTS}

Our study of childhood respiratory symptoms in low birthweight children has several features that contribute to avoid the bias inherent in most previous studies.

The study cohort was recruited into this prospective follow up study at the time of birth or entry into the neonatal units, and perinatal data were recorded at the time of discharge. Consequently their participation in the study was not influenced by the severity of their neonatal respiratory illness or their symptomatology later on in life. In addition, the cohort was recruited in a chronologically confined period of 12 months, and was drawn almost completely from the local population and immediately surrounding hospitals. There has only been one previous study that prospectively examined the respiratory symptomatology of prematurely born children, ${ }^{8}$ but this did not extend beyond 1 year of age.

Matched full term controls were not recruited in the neonatal period. Instead, when lung function tests started, a random sample of local schoolchildren was recruited as the reference group. Recruitment was based simply on the geographical location of their schools and on their date of birth. No attempt was made to select subjects in order to match the low birthweight cohort. Children were not excluded from the reference group on the basis of their previous respiratory history or symptoms. Indeed symptom questionnaires were not analysed until lung function data had been collected from both groups of children. Because the reference group was unselected, some disparities in their background compared with that of the low birthweight cohort were to be expected. In the reference group there were more non-white children (low birthweight $22 \%$, reference $44 \%$ ) and parents were more commonly either unskilled or unemployed (low birthweight $19 \%$, reference $42 \%$ ), although the two groups had the same proportion of boys (low birthweight $53 \%$, reference $54 \%$ ). In contrast with a previous report, however, we found no association between symptoms and low socioeconomic status or ethnic group. ${ }^{19}$ Such discrepancies did not affect our conclusions.

\section{QUESTIONNAIRE}

Two questionnaires were used to obtain the history for each child. The second self administered questionnaire, which was identical both in content and in method of administration to the parents of both groups of children, formed the main data base for this analysis. It was essential to ensure that both the questionnaire and the method of administration were identical because subtle changes in the wording of the questions could have influenced the response. ${ }^{20}$

The design of the second questionnaire was such that the questions were simple and most of the responses required a simple tick indicating 'yes' or 'no'. For most items the index of repeatability was high, suggesting that the questions were comprehended.

The questionnaire technique is not necessarily inferior to that of the interview technique in clinical research. The main disadvantage of the interview technique is that it is susceptible to observer bias. An interviewer who is aware whether the subject is in the study or control group may consciously or subconsciously probe harder for some responses while neglecting others. Such bias is probably common but is notoriously difficult to detect or to eliminate. It is important because it can substantially influence the findings of a study. The questionnaire method has the distinct advantage that if identical questionnaires are used and the mode of administration is similar, there is no room for observer bias.

In common with all clinical studies, a major uncertainty is recall bias by the respondents. Recent studies showing the lack of agreement between parental reports of recurrent sore throat compared with prospective monitoring, ${ }^{21}$ between reported 
respiratory illness compared with general practitioners records, ${ }^{22}$ and between diary scores of nocturnal cough compared with bedside tape recordings ${ }^{23}$ illustrate how much care is needed to validate reports of symptoms and illness. Because our low birthweight cohort had been seen at intervals since their discharge from our neonatal units (follow up at 3, 6, 9, 12, 18 months and 2, 3, and 5 years), we were able to verify that $74 \%$ and $75 \%$ of chest infections and hospital admissions for chest illness had already been documented in the first two years. Conversely, of the 14 and 18 children who had documented chest infection and hospital admissions, only two and one respectively were not reported as such by parents at 7 years. The number of admissions to hospital reported at 7 years was highly correlated with those documented in previous years $(r=0 \cdot 96)$. Our findings showed that misclassification due to parental failure to recall with respect to previous respiratory illnesses in the low birthweight cohort was small.

It was impossible to verify the reporting of such features as symptoms and cigarette consumption by parents. Accepting the fact that their verification was impracticable and probably technically impossible, we resorted to an alternative approach that was perhaps the next best. We examined the repeatability of the questionnaire responses. Although this did not test their validity, it reflected the general consistency of the responses obtained.

Although the same questions were asked and the overall repeatability compared favourably with other studies,${ }^{24}$ the repeatability of the responses $(x$ values) by the parents of the low birthweight children was in general better than that of the reference group. There are several possible explanations. Firstly, more parents of the reference group than the low birthweight cohort were of low socioeconomic status or from ethnic minorities. Secondly, the first questionnaire was administered to the parents of the low birthweight children by direct interview whereas that for the reference group was completed by the parents themselves without the assistance of an interviewer. Thirdly, the low birthweight children were recruited at or soon after the time of birth whereas the reference group was recruited at 7 years. The parents of the low birthweight cohort had been interviewed and questioned about their children's symptoms on a number of occasions in the previous years. This could enhance recall. The only way to avoid this form of bias would have been to recruit and subsequently monitor a concurrent full term control group. Finally, premature birth and its consequences may have heightened parental anxiety and influenced the perception and recollection of sym- ptoms many years later. Such bias was unavoidable and would not be removed even if a parallel group of healthy full term children had been recruited and followed up from the time of birth.

The reporting of symptoms in young children is substantially different from that in the older populations as it takes place at second hand. Consequently reporting of symptoms is biased by differences in perception and recall in individual parents. The prevalence of wheeze was no greater in low birthweight than in reference children. This argues against a major recall bias in the parents of low birthweight children. Furthermore reliable responses to questions on symptoms can only be obtained if they are easily recognised. Hence questions concerning symptoms that were more subjective in nature, such as chestiness or shortness of breath on exercise were omitted. At appropriate places in our questionnaire, we asked if the parents would like to report any other symptoms. Five low birthweight children were reported to have shortness of breath compared with none in the reference group.

\section{RESPIRATORY SYMPTOMS IN LOW BIRTHWEIGHT} CHILDREN

Wheeze and cough are the commonest respiratory symptoms in children. They may occur with or without an associated cold. The symptoms were commonly reported even among the healthy reference population of schoolchildren: $17 \%$ had cough and $16 \%$ had wheeze (table 4$)$. It is essential to compare the findings in low birthweight children with those of a large random sample extracted from the general population of children of the same age rather than with 'normal' controls. Ideally the study and the reference group should have been matched for all possible confounding variables. In our study, we opted for an unselected random sample of local schoolchildren as our reference group. There was an excess of children of non-white origin and lower socioeconomic status due to an excess of single parent families. If these factors had had any detectable adverse influence on respiratory health it would be to minimise the difference found between the two groups and would not affect our conclusions. In any case, in testing the hypothetical association between long term symptomatology and neonatal respiratory treatment, these were adjusted for by statistical techniques.

Despite the increasing survival of prematurely born infants, the amount of literature on the long term respiratory symptomatology in these children is surprisingly scanty. Various indices of respiratory morbidity had been used in previous studies. Some were based on clinical diagnosis, some based on 
lower respiratory tract infection with changes in chest radiographs ${ }^{5}$ or requiring admission to hospital, ${ }^{25} 26$ whereas others were concerned with wheeze ${ }^{3}{ }^{27}$ Based on different criteria these studies, mostly reported in the 1970 s, did not find increased wheeze or respiratory morbidity in prematurely born children or survivors of respiratory distress syndrome in childhood. It appeared, therefore, that complete recovery was the rule. These studies are difficult to interpret, however, as many of them did not include a matched control group. ${ }^{5} 62728$ Moreover, many of these studies were designed primarily to examine outcome by other techniques. Because of their small study size, these studies had poor statistical power to test for a difference between groups. Not surprisingly, therefore, respiratory symptoms in long term survivors were either mentioned in passing or omitted altogether by many previous investigators.

We found that low birthweight children were no more likely to wheeze than a random population of children of the same age. Nor was a history of asthma more common in low birthweight subjects or in their parents than in the reference group. ${ }^{16}$ The major difference in symptoms between the low birthweight and reference population was in the prevalence of cough. The possibility that the increase in cough in the low birthweight cohort might have been due to better recall by their parents was not supported by any increase in wheeze in these children.

In addition to an increase in the prevalence of previous chest infections and hospital admissions, a history of whooping cough was also more common in the low birthweight children. This could be due to differences in pertussis vaccination rate as at the time there had been a reluctance to give such vaccinations to low birthweight children. Some of the 'frequent troublesome cough' in these children could have been attributed to whooping cough (pertussis syndrome).

\section{ASSOCIATION BETWEEN RISK FACTORS AND LONG TERM} SYMPTOMATOLOGY

In contrast with the reference group, in the low birthweight cohort there was a significant association between wheeze at 7 years and maternal smoking (table 6). A link between maternal smoking and the respiratory health of their children has previously been reported in epidemiological studies. ${ }^{29-33}$ It is independent of many other confounding variables, and is probably a causal association that could be effected either postnatally or antenatally. ${ }^{34} 35$ Within the relatively small study size of the low birthweight cohort $(n=121)$, it was not possible to determine which of these was the case, as less than
$20 \%$ of mothers who smoked altered their smoking habits in relation to pregnancy.

The lack of a significant association between wheeze and a positive family history of asthma in the low birthweight cohort is surprising given the strength of the association in the reference group (table 5). It suggests that other factors were predominant, and that our study was too small to enable us to detect an additional familial factor. Although there was no excess of wheeze in the low birthweight children compared with a random sample of healthy schoolchildren, both maternal smoking as well as neonatal oxygen score were weakly associated with the symptom at 7 years. The overall findings suggest that a family history of asthma does not significantly increase the risk of wheeze in the long term low birthweight survivors.

The association between neonatal oxygen score and childhood cough was not uniform in the cohort. The excess of cough was especially pronounced in the very low birthweight children who received neonatal intensive care (figure). This contrasts with the very low prevalence of symptoms in the other very low birthweight children who did not receive neonatal respiratory treatment. It is probable that very low birthweight children were more vulnerable to the effect of neonatal respiratory treatment than the remainder of the cohort and that the symptom that they manifested at the age of 7 was cough rather than wheeze. The hypothetical association between the symptoms at 7 years and the level of neonatal respiratory treatment (oxygen score) was confirmed by multiple logistic regression analysis, allowing for other variables which could have influenced the occurrence of symptoms.

Although the association between childhood symptoms and oxygen score confirmed that the former could be attributable to the level of neonatal intensive care received, it does not prove that the association is causal. It remains possible that their association was linked by other confounding factors such as host vulnerability, leading to both an increase in the level of neonatal respiratory treatment required as well as long term respiratory symptomatology. The relatively low level of symptoms, especially wheeze, in the low birthweight children compared with the reference group argues against the association being the result of preferential recall bias by their parents. But it also implies that even if the association were causal, the scope for improvement in symptoms in long term survivors might be limited. Similarly, though neonatal lung injury is clearly associated with mechanical ventilation, ${ }^{36}$ there was no significant excess of symptoms in those who received this form of treatment compared with those who had oxygen treatment 
alone. Although this is a welcome finding, it does suggest that the potential for improving long term symptomatology through continuing advances in neonatal ventilatory technology is not great. Among all the perinatal risk factors examined, maternal smoking was the only significant factor that might be amenable to manipulation. With evidence that the effect of maternal smoking could be due to both antenatal and well as postnatal exposure, it would be important to advise abstention early in pregnancy or before conception.

In conclusion, we have found a relatively small excess of coughing in 7 year old children of low birthweight compared with a random sample of healthy schoolchildren of the same age. This symptom has been overlooked by previous studies. Its significance in the low birthweight cohort was confirmed by its association with the level of neonatal respiratory treatment. With progressive reduction in the level of symptoms experienced by the low birthweight cohort over the previous few years, one can afford to be optimistic about the long term outlook. This speculation could only be confirmed by longitudinal studies in subsequent years.

We thank the education department of the London Borough of Ealing, the staff and pupils of East Acton First School, Berrymede and Derwentwater junior schools, and the parents and children of the low birthweight cohort for their enthusiastic support in this project. The work was supported by grants from the Good Neighbours Trust, Moorgate Trust Foundation, C \& A Charitable Trust, Sue Hammerson OBE, the Spastics Society, Fisons Pharmaceuticals, and Glaxo UK.

We also thank Dr Anne Cartwright and Mr Vic Aber for much helpful advice and Mrs Barbara Reed for organising the lung function clinics. The cohort was initially enrolled due to the efforts of Drs Pamela Davies, David Harvey, and David Starte.

\section{References}

1 Outerbridge EW, Nogrady MB, Beaudry PH, et al. Idiopathic respiratory distress syndrome. Am J Dis Child 1972;123:99-104.

2 Bryan MH, Hardie MJ, Reilly BJ, et al. Pulmonary function studies during the first year of life in infants recovering from the respiratory distress syndrome. Pediatrics 1973;52:169-78.

3 Johnson JD, Malachowski NC, Grobstein R. Prognosis of children surviving with the aid of mechanical ventilation in the newborn period. J Pediatr 1974;84:272-6.

${ }^{4}$ Stocks J, Godfrey S, Reynolds EOR. Airway resistance in infants after various treatments for hyaline membrane disease: special emphasis on prolonged high levels of inspired oxygen. Pediatrics 1978;61:178-83.

${ }^{5}$ Fitzhardinge PM. Follow-up studies in infants treated by mechanical ventilation. Clin Perinatol 1978;5:451-61.

${ }^{6}$ Lindroth M, Jonson B, Svenningsen NW, et al. Pulmonary mechanics, chest $\mathrm{X}$-ray and lung disease after mechanical ventilation in low birth weight infants. Acta Paediatr Scand 1980;69:761-70.

7 Wong YC, Beardsmore CS, Silverman M. Pulmonary sequelae of neonatal respiratory distress in very low birthweight infants: a clinical and a physiological study. Arch Dis Child 1982;57: 418-24.
${ }^{8}$ Myers MG, McGuinness GA, Lachenbruch PA. Respiratory illnesses in survivors of infants respiratory distress syndrome. Am Rev Respir Dis 1986;133:1011-8.

9 Gerhardt T, Hehre D, Feller R, et al. Serial determination of pulmonary function in infants with chronic lung disease. $J$ Pediatr 1987;110:448-56.

10 Lamarre A, Linsao L, Reilly BJ, et al. Residual pulmonary abnormalities in survivors of idiopathic respiratory distress syndrome. Am Rev Respir Dis 1973;108:56-61.

11 Heldt GP, McIlroy MB, Hansen TN, et al. Exercise performance of the survivors of hyaline membrane disease. J Pediatr 1980;96:995-9.

12 Stahlman M, Hedvall G, Lindstrom D, et al. Role of hyaline membrane disease in production of later childhood lung abnormalities. Pediatrics 1982;69:572-6.

13 Borkenstein J, Borkenstein M, Rosegger H. Pulmonary function studies in long-term survivors with artificial ventilation in the neonatal period. Acta Paediatr Scand 1980;69:159-63.

14 Mansell AL, Driscoll JM, James LS. Pulmonary follow-up of moderately low birthweight infants with and without respiratory distress syndrome. J Pediatr 1987;110:111-5.

15 Riedel F. Long term effects of artificial ventilation in neonates. Acta Paediatr Scand 1987;76:24-9.

16 Chan KN, Noble-Jamieson CM, Elliman A, Bryan EM, Aber VR, Silverman M. Airway responsiveness in low birthweight children and their mothers. Arch Dis Child 1988;63:905-10.

$17 \mathrm{du}$ V Florey C, Leeder SR. Methods of cohort studies of chronic airflow limitation. Geneva: WHO Regional Publications, 1982.

${ }^{18}$ Baker RJ. The GLIM system: release 3. London: Royal Statistical Society, 1978.

19 Johnston IDA, Bland TM, Anderson HR. Ethnic variation in respiratory morbidity and lung function in childhood. Thorax 1987;42:542-8.

${ }^{20}$ Hedges BM. Question wording effects: presenting one or both sides of a case. The Statistician 1978;28:83-99.

21 Paradise JL, Bluestone CD, Bachman RZ, et al. History of recurrent sore throat as an indication for tonsillectomy. $N$ Engl $J$ Med 1978;298:409-13.

22 Watkins CJ, Burton P, Leeder S, et al. Doctor diagnosis and maternal recall of lower respiratory illness. Int J Epidemiol 1982;11:62-6.

23 Archer LNJ, Simpson H. Night cough counts and diary card scores in asthma. Arch Dis Child 1985;60:473-5.

24 Salome CM, Peat JK, Britton WJ, et al. Bronchial hyperresponsiveness in two populations of Australian school children. Relation to respiratory symptoms and diagnosed asthma. Clin Allergy 1987;11:271-8.

${ }^{25}$ Bryan MH, Levison H, Swyer PR. Pulmonary function in infants and children following acute neonatal respiratory distress syndrome. Bull Physiopath Respir 1973;9:1587-600.

26 Dinwiddie R, Mellor DH, Donaldson SH, et al. Quality of survival after artificial ventilation of the newborn. Arch Dis Child 1974;49:703-10.

27 Stahlman M, Hedvall G, Dolanski E, et al. A six-year follow-up of clinical hyaline membrane disease. Pediatr Clin North Am 1973;20:433-46.

${ }^{28}$ Kamper J. Long term prognosis of infants with severe idiopathic respiratory distress syndrome II. Cardiopulmonary outcome. Acta Paediatr Scand 1978;67:71-6.

29 Weiss ST, Tager IB, Speizer FE, et al. Persistent wheeze: its relation to respiratory illness, cigarette smoking and level of pulmonary function in a population sample of children. Am Rev Respir Dis 1980;122:697-707.

30 Colley JRT, Holland WW, Corkhill RT. Influence of passive smoking and parental phlegm on pneumonia and bronchitis in early childhood. Lancet 1974;ii:1031-4.

31 Yarnell JWG, St Leger AS. Respiratory illness, maternal smoking habit and lung function in children. $\mathrm{Br} J$ Dis Chest 1979;73:230-6.

${ }^{32}$ Hasselblad V, Humble CG, Graham MG, et al. Indoor 
environmental determinants of lung function in children. $A m$ Rev Respir Dis 1981;123:479-85.

33 Tager IB, Weiss ST, Munoz A, et al. Longitudinal study of the effects of maternal smoking on pulmonary function. $N$ Engl $J$ Med 1983;309:699-703.

34 Simpson RJ, Smith NGA. Maternal smoking and low birthweight: implications for antenatal care. J Epidemiol Community Health 1986;40:223-7.

35 Taylor B, Wadsworth J. Maternal smoking during pregnancy and lower respiratory tract illness in early life. Arch Dis Child 1987;62:786-91.
36 O'Brodovich HM, Mellins RB. Bronchopulmonary dysplasia: unresolved neonatal acute lung injuries. Am Rev Respir Dis 1985;132:694-709.

Correspondence to Dr M Silverman, Department of Paediatrics and Neonatal Medicine, Royal Postgraduate Medical School, Hammersmith Hospital, Du Cane Road, London W12 0HS.

Accepted 19 April 1989 